Original Article

\title{
Effect of Forward and Backward Locomotion Training on Anaerobic Performance and Anthropometrical Composition
}

\author{
Shaji John Kachanathu, PT, PhD ${ }^{1)^{*}}$, Ageel M Alenazi, PT ${ }^{2)}$, Abdulrahman D Algarni, MD ${ }^{3)}$, \\ Ashraf Ramadan Hafez, PT, PhD ${ }^{4}$, Unaise A Hameed, PT, PhD ${ }^{5)}$, Shibili Nuhmani, PT, PhD ${ }^{5}$, \\ Mansour S Alghamdi, $\mathrm{PT}^{1)}$, Ganeshwerarao Melam, $\mathrm{PT}^{1)}$ \\ 1) Department of Rehabilitation Health Sciences, College of Applied Medical Sciences, King Saud \\ University: Building 24, Office 2083, PO Box 10219, Riyadh 11433, Kingdom of Saudi Arabia \\ 2) Salman Bin Abdulaziz University, Kingdom of Saudi Arabia \\ 3) Department of Orthopaedic, King Saud University, Kingdom of Saudi Arabia \\ 4) Cairo University Hospital, Egypt \\ 5) Jamia Hamdard University, India
}

\begin{abstract}
Purpose] Forward walking (FW) and backward walking (BW) on a treadmill is a common tool for lower extremity rehabilitation in the clinical setting. The purpose of this study was to evaluate the effects on anaerobic performance and anthropometrical adaptations during FW and BW on a treadmill. [Subjects and Methods] A convenience sample of thirty healthy male subjects with a mean age of $20.93 \pm 2.54$ years participated in this study. Subjects were divided into 2 groups, a Forward Walking Group (FWG) $(\mathrm{n}=15)$ and a Backward Walking Group (BWG) $(\mathrm{n}=15)$, which performed $\mathrm{FW}$ and $\mathrm{BW}$ on a treadmill at $10^{\circ}$ inclination, respectively. The training consisted of three sessions per week for 6 weeks. Study outcomes such as anaerobic performance and anthropometrical body composition were measured at pre- and post-intervention. [Results] Both FW and BW improved anaerobic performance significantly, and the BW group showed better performance than FW. However, changes in anthropometrical body composition were found to be not significant after six weeks of intervention in both the FW and BW groups. [Conclusions] BW training in rehabilitation can be considered more effective than FW at improving anaerobic performance. We also conclude that six weeks of FW and BW training is insufficient for eliciting changes in the body composition.
\end{abstract}

Key words: Backward walking, Anaerobic, Body composition

(This article was submitted Apr. 3, 2014, and was accepted Jun. 5, 2014)

\section{INTRODUCTION}

Physical inactivity is being increasingly recognized as a major problem in global health. The World Health Organization (WHO) estimates that 3.3 million people die around the world each year due to physical inactivity, making it the fourth leading underlying cause of mortality ${ }^{1}$. It is not surprising that physical inactivity has a substantial cost burden in addition to a large health burden. The current guidelines on cardiovascular disease prevention recommend at least 30 minutes of moderate intensity physical activity on five or more days per week or 20 minutes of vigorous exercise on three days per week ${ }^{2}$.

Physical activities of moderate intensity, such as walking, jogging, and running can be incorporated into everyday

*Corresponding author. Shaji John Kachanathu (E-mail: johnsphysio@gmail.com)

(C2014 The Society of Physical Therapy Science. Published by IPEC Inc. This is an open-access article distributed under the terms of the Creative Commons Attribution Non-Commercial No Derivatives (by-ncnd) License $<$ http://creativecommons.org/licenses/by-nc-nd/3.0/>. life. Walking has been established as a form of endurance training for injury prevention and has sufficient training effects with little risk of overstrain ${ }^{3)}$. Walking is a popular, convenient, and relatively safe form of exercise and also holds great promise for weight management ${ }^{4}$.

Walking has long been used by both fitness and rehabilitation professionals to improve cardiovascular fitness and to rehabilitate musculoskeletal injuries. Humans generally learn to walk and run in a forward direction with little difficulty. This is inherently logical since our field of view is in the forward direction. Because of its functionality, most walking studies and clinical protocols have involved forward walking (FW). Backward walking (BW) reverses leg movement trajectories: the leg not only reverses its direction of movement, it also travels in the opposite direction along virtually the same path as in $\mathrm{FW}^{5)}$. It has been reported that BW has training effects that are different from those of $\mathrm{FW}^{6}$. Furthermore, running or walking backward is used as a preferred rehabilitation exercise for some conditions, in particular when the impact of heel strike needs to be avoided ${ }^{7}$. However, the different effects of FW and BW in terms of their physiological aspects are still unknown. 
The purpose of this study was to compare forward and backward locomotion training and their effects on physical performance, such as anaerobic capacity, and anthropometrical body composition.

\section{SUBJECTS AND METHODS}

A convenience sample of 30 healthy male subjects with a mean age of $20.93 \pm 2.54$ years, a mean weight of $59.43 \pm$ $5.38 \mathrm{~kg}$, and a mean height of $1.69 \pm 0.05 \mathrm{~m}$ were recruited on a university campus for this study. The present study was reviewed and approved by the institutional ethical committee and written consent was obtained prior to the study from all the participants. Inclusion criteria for study participation were: healthy young males, aged between $18-28$ years, normal BMI and no active exercise/sports participation. Subjects with any lower extremity injury in the past 6 months, cardiac or metabolic condition, or back, hip, knee or ankle dysfunctions were excluded. Subjects were selected following the inclusion and exclusion criteria, and were randomly and evenly divided into 2 groups: the Forward Walking Group (FWG), and the Backward Walking Group (BWG) $(\mathrm{n}=15$ in each group). FWG and BWG performed forward and backward walking, respectively.

Pre- and post-test anaerobic performance was calculated from the results of the Running-based Anaerobic Sprint Test $(\text { RAST })^{8,9)}$. A warm-up of light jogging for 5 minutes was followed by 5 minutes rest. Then, each subject performed six sprints over 35 meters with a 10 -second rest between each sprint. The time taken for each sprint along with body weight was used to calculate RAST.

Power $=$ Body Weight $\times$ Distance $^{2} \div$ Time $^{3}$; Average Power $(\mathrm{AP})=$ Sum of all six values $\div 6$

Pre- and post-test anthropometrical body composition measurements were used to calculate Body Density $(\mathrm{Db})^{10)}$, Percentage Body Fat $(\% \mathrm{BF})^{11)}$, Fat Mass $(\mathrm{FM})^{12)}$, Fat Free Body Mass $(\mathrm{FFM})^{12)}$. Based on anatomical landmarks in the Anthropometric Standardization Reference Manual, the skin folds of the triceps, subscapula, and abdomen were used to calculate $\mathrm{Db}$. The average values of the three skin folds sites, i.e. triceps, subscapula, and abdomen were summed ( $\left.\sum 3 \mathrm{SKF}\right)$ and entered into the equation to determine $\mathrm{Db}$, which was subsequently used to calculate $\% \mathrm{BF}$, FM and FFM.

$$
\begin{aligned}
\mathrm{Db}=[1.0973-(0.000815 \times & \left.\left.\sum 3 \mathrm{SKF}\right)\right]+ \\
& {\left[0.00000084 \times\left(\sum 3 \mathrm{SKF}\right)^{2}\right] . }
\end{aligned}
$$

Percentage body fat $(\% \mathrm{BF})=[495 \div$ Body Density $(\mathrm{Db})]-450$.

Fat Mass $(\mathrm{FM})=$ Body Mass $\times \% \mathrm{BF} / 100$;

Fat Free Body Mass $($ FFM $)=$ Body Mass - FM.

The subjects were given a familiarization session on the treadmill one week prior to the start of the training of either FW/BW at a self-selected speed, without inclination 3 supervised 10 minute sessions. At the start of the intervention, the treadmill was calibrated and adjusted to produce a constant speed of $4.0 \mathrm{mph}$ and an uphill inclination of 10 degree $^{13)}$. The subjects were given 1 minute of accommodation followed by 6 minutes of training. The purpose of the accommodation phase was to gradually increase the speed and the inclination of the treadmill to acclimatize the subjects to the walking pattern and to set the training parameters to the desired training levels. The FWG performed 6 minutes of forward treadmill walking at an inclination of $10^{\circ}$ and a constant speed of $4 \mathrm{mph}, 3$ sessions per week, for a period of 6 weeks with one day rest between sessions. The BWG performed backward treadmill walking at the same speed and inclination with the same training schedule.

Outcome measures such as anaerobic performance and anthropometrical body composition (i.e. $\mathrm{Db}, \% \mathrm{BF}, \mathrm{FM}$, and FFM) were measured pre- and post-intervention. The statistical software package, SPSS version 17, was used for data analysis. The values are reported as mean \pm SD. The unpaired Student's t-test was used to examine the significance of group differences for all the dependent variables and the paired t-test was used to analyze within group differences.

\section{RESULTS}

Within group analysis of anaerobic performance showed significant differences within both FWG and BWG $(p=$ 0.001 and $p=0.000$ respectively; Table 1 ). However, within group analysis of the pre- and post-test values of anthropometrical body composition found no significant differences for $\mathrm{DB}(\mathrm{p}=0.164 \mathrm{p}=0.082, \mathrm{BF} \%(\mathrm{p}=0.164 \mathrm{p}=0.082, \mathrm{FM}$ $(p=0.165 p=0.083$, and FFM $(p=0.165 p=0.083)$ after FW and BW training, respectively (Table 1).

When FWG and BWG were compared using the independent t-test for the effect of FW and BW on the treadmill, a statistically significant difference $(p=-0.033)$ in anaerobic performance was found, and the mean improvement of BWG (12.06 \pm 6.95 watts) was more than the mean improvement of FWG (7.00 \pm 5.34 watts).

Moreover, between group analysis of $\mathrm{Db}, \% \mathrm{BF}, \mathrm{FM}$, and FFM found no significant differences between FWG and BWG $(p=0.621 p=0.632 p=0.710$ and $p=0.710$, respectively).

\section{DISCUSSION}

The present study revealed significant improvements in anaerobic power were elicited FW and BW training and greater improvement was shown by BWG than by FWG. In contrast, 6 weeks of $\mathrm{FW}$ and $\mathrm{BW}$ intervention elicited no statistically significant changes in the body composition values of $\mathrm{Db}$, \% BF, FM, or FFM.

There are several possible reasons for the anaerobic improvement. BW is a novel task in which a larger number of motor units may be recruited, and this may result in increased energy utilization. Increased motor unit recruitment would result in a greater amount of skeletal muscle activation than in an equivalent familiar task. Schwane et al. reported that a relatively new motor task increases motor unit recruitment, thus increasing the metabolic cost of the activity $^{14)}$. A recent study also demonstrated an improvement elicited by Nordic BW training, due to more efficient motor unit recruitment and as a result of practice ${ }^{15)}$. Oth- 
Table 1. Comparison of anaerobic capacity and body composition between FWG and BWG

\begin{tabular}{lrrcr}
\hline Variables & \multicolumn{2}{c}{ FWG } & \multicolumn{2}{c}{ BWG } \\
\cline { 2 - 5 } & Pre-test & Post-test & Pre-test & Post-test \\
\hline AP $($ watts $)$ & $317.9 \pm 32$ & $324.4 \pm 33$ & $317.1 \pm 43$ & $329.1 \pm 44$ \\
$\mathrm{Db}^{*}\left(\mathrm{~g} / \mathrm{cm}^{3}\right)$ & $1.1 \pm 0.1$ & $1.1 \pm 0.1$ & $1.1 \pm 0.1$ & $1.1 \pm 0.1$ \\
$\% \mathrm{BF} *(\%)$ & $15.2 \pm 2.7$ & $15.2 \pm 2.7$ & $14.9 \pm 2.6$ & $14.9 \pm 2.6$ \\
$\mathrm{FM}^{*}(\mathrm{kgs})$ & $9.1 \pm 2.5$ & $9.1 \pm 2.5$ & $9.1 \pm 2.4$ & $9.0 \pm 2.4$ \\
$\mathrm{FFM}^{*}(\mathrm{kgs})$ & $50 \pm 3.4$ & $50 \pm 3.4$ & $50.8 \pm 3$ & $50.8 \pm 3$ \\
\hline
\end{tabular}

*Non-significant

ers have also suggested that BW imposes a greater burden on the medial sensorimotor cortices ${ }^{16)}$, and that BW elicits greater activity in the medial motor cortices than forward walking ${ }^{17)}$. Consequently, greater motor unit recruitment may increase oxygen demand to the point that the muscle contractile output requires greater support through anaerobic pathways.

Vilensky et al. reported that BW was different from FW. They observed that BW was associated with increased cadence and decreased stride length compared to $\mathrm{FW}^{6}$ ). It has been reported that the muscle action of the knee extensors is largely eccentric and concentric during $\mathrm{FW}$, while it is isometric and concentric during $\mathrm{BW}^{18)}$. Concentric muscle contraction has been shown to have a higher energy cost than eccentric muscle work, and a dramatically higher energy cost than that of eccentric resistance was reported in the performance of concentric cycle ergometry ${ }^{19)}$. It is postulated that during concentric contractions, when the muscle fiber cross bridge has completed its power stroke and produced shortening, ATP is required for detachment and resetting of cross bridges. Conversely, during eccentric contractions the cross bridge is forcibly detached and reattached without further ATP splitting ${ }^{19)}$. It has also been reported that the work of the knee extensor increases during the stance phase of backward running when compared with forward running ${ }^{20)}$. Devita et al. reported that total lower extremity muscle work was similar during forward running and backward running at the same speed despite a significant change in muscle power and work output ${ }^{21)}$. This could be the reason behind the anaerobic power improvements observed in both FWG and BWG.

The body composition changes in the FW and BW groups were found to be not significant $(\mathrm{p}>0.05)$. Similarly, Hinkleman et al. suggested that moderate exercise training alone may not be sufficient to affect body composition ${ }^{22)}$. Walker et al. also observed that normoglycemic women failed to lose body fat after 12 weeks of exercise in a walking program $^{23)}$. It has also been demonstrated that the joint torque profiles of the hip and knee in BW are quite similar to those of FW with a reverse sequence, but with different time durations of flexion and extension ${ }^{24)}$. These findings are also supportive of the lack of impact on body composition observed in the FWG and the BWG in the present study. However, it is also true that the kinetic factors of ankle power and workload are lower during backward walking than in forward walking. During backward walking plantar flex- ion plays only a small role in propulsion, and the propulsive force in backward walking may come from segments other than the ankle. Possible sources of the propulsive force are strategies involving hip power and the center of gravity ${ }^{25)}$. Walking speed and the mobility improvements have also been observed after backward treadmill walking with Body Weight Support (BWS) in the early phase of stroke, and it is postulated that $\mathrm{BW}$ is superior to $\mathrm{FW}$ at increasing the exercise intensity of muscle activities because it requires higher energy consumption, even in a short period of time ${ }^{26)}$. Positive correlations have been reported between the acceleration values of $\mathrm{C} 7$ and S2 and the muscular strengths of the hamstrings, tibialis anterior, and triceps surae, and these muscles contribute to acceleration of the trunk in the backward stepping reaction ${ }^{27}$.

Though BW has been proven to demand greater metabolic activity than its counterpart, forward walking, the exercise intensity might not have been sufficient enough to elicit a change in body composition in our present study. The training duration is a possible reason for the lack of significant changes observed in body composition in the present study.

The high levels of blood lactate measured in the study done by Flynn et al. suggest backward walking relies on a higher percentage of anaerobic metabolism than forward walking ${ }^{18)}$. Therefore, our study results are supportive of previous findings, and we assume that higher metabolic demand is one reason for the changes in anaerobic performance observed in the backward walking group in the present study. However, these aspects need to be further investigated.

The present study was limited by the inclusion of participants with lower than normal BMI. We recommend conducting further studies to further explore the effects of forward and backward walking training on body composition values of overweight and obese groups of subjects.

We conclude that both backward and forward walking improve anaerobic performance, but not anthropometrical body composition values. Also, backward walking is more effective than forward walking at improving anaerobic performance.

\section{ACKNOWLEDGEMENTS}

The authors extend their appreciation to the College of Applied Medical Sciences Research Centre and the Dean- 
ship of Scientific Research at King Saud University for funding this research.

\section{REFERENCES}

1) World Health Organization, editor: Global health risks: mortality and burden of disease attributable to selected major risks. World Health Organization, 2009

2) Haskell WL, Lee IM, Pate RR, et al. American College of Sports Medicine American Heart Association: Physical activity and public health: updated recommendation for adults from the American College of Sports Medicine and the American Heart Association. Circulation, 2007, 116: 1081-1093. [Medline] [CrossRef]

3) Schwarz M, Urhausen A, Schwarz L, et al.: Cardiocirculatory and metabolic responses at different walking intensities. Br J Sports Med, 2006, 40 64-67. [Medline] [CrossRef]

4) Browning RC, Kram R: Energetic cost and preferred speed of walking in obese vs. normal weight women. Obes Res, 2005, 13: 891-899. [Medline] [CrossRef]

5) Thorstensson A: How is the normal locomotor program modified to produce backward walking? Exp Brain Res, 1986, 61: 664-668. [Medline] [CrossRef]

6) Vilensky A, Gankiewicz E, Gehlsen G: A kinematic comparison of backward and forward walking in humans. Hum Move Stud. 1987, 13: 29-50.

7) Roos PE, Barton N, van Deursen RW: Patellofemoral joint compression forces in backward and forward running. J Biomech, 2012, 45: 1656-1660. [Medline] [CrossRef]

8) Zagatto AM, Beck WR, Gobatto CA: Validity of the running anaerobic sprint test for assessing anaerobic power and predicting short-distance performances. J Strength Cond Res, 2009, 23: 1820-1827. [Medline] [CrossRef]

9) Zacharogiannis E, Paradisis G, Tziortzis S: An evaluation of tests of anaerobic power and capacity. Medicine \& Science in Sports \& Exercise, 2004, 36: S116.

10) Lohman TG: Skinfolds and body density and their relation to body fatness: a review. Hum Biol, 1981, 53: 181-225. [Medline]

11) Siri WE: Body composition from fluid spaces and density: Analysis of methods. In: Brozek J, Hensschel A (eds). Techniques of Measuring Body Composition. Washington: National Academy of Sciences-National Research Council, 1963, 224-44.

12) McArdle WD, Katch FI, Katch VL: Exercise Physiology: Energy, Nutrition, and Human Performance, 6th ed. Philadelphia: Lippincott Williams \& Wilkins, 2001

13) Cipriani DJ, Armstrong CW, Gaul S: Backward walking at three level of treadmill inclination: an electromyographic and kinematic analysis. J Orthop Sports Phys Ther, 1995, 22: 95-102. [Medline] [CrossRef]

14) Schwane JA, Johnson SR, Vandenakker CB, et al: Delayed-onset muscular soreness and plasma CPK and LDH activities after downhill running. Med Sci Sports Exerc, 1983, 15: 51-56. [Medline] [CrossRef]

15) Shigemori K, Nagino K, Nakamata E, et al.: Motor learning in the community-dwelling elderly during Nordic backward walking. J Phys Ther Sci, 2014, 26: 741-743. [Medline] [CrossRef]

16) Kurz MJ, Wilson TW, Arpin DJ: Stride-time variability and sensorimotor cortical activation during walking. Neuroimage, 2012, 59: 1602-1607. [Medline] [CrossRef]

17) Zelenin PV, Deliagina TG, Orlovsky GN, et al.: Activity of motor cortex neurons during backward locomotion. J Neurophysiol, 2011, 105: 26982714. [Medline] [CrossRef]

18) Flynn TW, Soutas-Little RW: Mechanical power and muscle action during forward and backward running. J Orthop Sports Phys Ther, 1993, 17: 108-112. [Medline] [CrossRef]

19) Flynn TW, Connery SM, Smutok MA, et al.: Comparison of cardiopulmonary responses to forward and backward walking and running. Med Sci Sports Exerc, 1994, 26: 89-94. [Medline] [CrossRef]

20) Mackie JW, Dean TE: Running backward training effects on upper leg musculature and ligamentous instability of injured knees. Med Sci Sports Exerc, 1984, 16: 151. [CrossRef]

21) DeVita P, Stribling J: Lower extremity joint kinetics and energetics during backward running. Med Sci Sports Exerc, 1991, 23: 602-610. [Medline] [CrossRef]

22) Hinkleman LL, Nieman DC: The effects of a walking program on body composition and serum lipids and lipoproteins in overweight women. J Sports Med Phys Fitness, 1993, 33: 49-58. [Medline]

23) Walker KZ, Piers LS, Putt RS, et al.: Effects of regular walking on cardiovascular risk factors and body composition in normoglycemic women and women with type 2 diabetes. Diabetes Care, 1999, 22: 555-561. [Medline] [CrossRef]

24) Kwon HJ, Xiang Y, et al.: Backward walking simulation of humans using optimization. Structural and Multidisciplinary Optimization. 2014, 1-11. [CrossRef]

25) Soda N, Ueki T, Aoki T: Three-dimensional motion analysis of the ankle during backward walking. J Phys Ther Sci, 2013, 25: 747-749. [Medline] [CrossRef]

26) Takami A, Wakayama S: Effects of partial body weight support while training acute stroke patients to walk backwards on a treadmill - A controlled clinical trial using randomized allocation. J Phys Ther Sci, 2010, 22: 177-187. [CrossRef]

27) Takeuchi Y, Miwa M, Aoki C: Relationship between muscular strength of the lower extremities and trunk acceleration during backward stepping by the elderly. J Phys Ther Sci, 2010, 22: 167-171. [CrossRef] 